\title{
Percepções sobre a mediação cultural em bibliotecas na literatura nacional e estrangeira
}

\author{
Perceptions on cultural mediation in libraries concerning/Related \\ to national and international literature
}

\author{
Alessandro RASTELI' \\ Rosângela Formentini CALDAS ${ }^{1}$
}

\section{Resumo}

Nas últimas décadas, o termo mediação ganhou cada vez mais projeção em estudos e pesquisas na Ciência da Informação. Contudo, apesar de trabalhada nesta área do conhecimento, a mediação, em um contexto cultural, ainda é um conceito embrionário e premente de uma construção de sentidos mais sólida. Desse modo, o estudo tem como objetivo empreender um levantamento bibliográfico de textos produzidos tanto no Brasil quanto em outros países, com ênfase, porém, na França, local com proeminente produção sobre o tema, a fim de explicitar o conceito de mediação. Dessa maneira, tenta-se promover conexões que avancem na compreensão e definição da mediação cultural no contexto da biblioteca, tão plural e complexo, avançando na compreensão e definição da mediação cultural no contexto da biblioteca. Utilizou-se, como procedimento metodológico, pesquisa de abordagem qualitativa, exploratória, cujo método utilizado foi a pesquisa bibliográfica. Os resultados apontam que o conceito de mediação ganha destaque por sua centralidade nas interações sociais e mediações simbólicas, passando a ser compreendido como uma ação inerente a todo fazer do profissional da informação, dando maior relevo à responsabilidade social desse agente mediador e também da biblioteca enquanto espaço de construção de sentidos.

Palavras-chave: Apropriação cultural. Biblioteca. Bibliotecário. Cultura e informação. Mediação cultural.

\begin{abstract}
In recent decades the term mediation has been gaining increasing attention in studies and research in Information Science. However, although mediation is a concept studied in Information Science, it is still incipient in a cultural context requiring the development of further reliable/consistent meanings. Thus, the aim of the study was to conduct a survey in Brazilian and foreign literature (with emphasis on the French literature, as there is a prominent production on the subject in French) in order to clarify the concepts. Reflecting on these concepts, we endeavor to make connections that favor a broader understanding of the area, which is plural and complex, advancing the understanding and definition of cultural mediation in the context of libraries. The methodological procedures used were the qualitative, exploratory research and a bibliographical research method. The results show that the concept of mediation is highlighted by its centrality in social interactions and symbolic mediations, now understood as an action inherent to every information professional, with greater social responsibility weight on the professional and the library environment as it is a place for the development of meanings.
\end{abstract}

Keywords: Cultural appropriation. Library. Librarian. Culture and information. Cultural mediation.

\footnotetext{
1 Universidade Estadual Paulista Júlio de Mesquita Filho, Departamento de Ciência da Informação, Programa de Pós-Graduação em Ciência da Informação. Av. Higino Muzi Filho, 737, Mirante, 17525-900, Marília, SP, Brasil. Correspondência para/Correspondence to: R. F. CALDAS. E-mail: <rcaldas@marilia.unesp.br>.

Apoio: Fundação de Amparo à Pesquisa do Estado de São Paulo (Processo no 2015/22142-7).

Recebido em 28/3/2016 e aprovado para publicação em 31/1/2017.
} 


\section{Introdução}

A premissa de que a biblioteca é uma instituição essencial à sociedade baseia-se no fato de que esta deve auxiliar na garantia do pleno exercício dos direitos dos indivíduos junto à sociedade. Para que se estabeleça o devido exercício da cidadania, as bibliotecas necessitam desenvolver as suas funções educacionais, culturais, artísticas, de lazer e informacionais.

No que tange ao âmbito da cultura, presencia-se, na contemporaneidade, alguns fenômenos culturais decorrentes das sociedades pós-modernas e que resultam em fatores que devem ser refletidos pelos profissionais de informação. Entre eles estão, por exemplo, o acesso à cultura, as identidades culturais, as políticas de preservação cultural e artística, as imigrações e o gerenciamento, acesso, criação, difusão e apropriação de bens culturais.

O papel da biblioteca amplia-se quando colocado sob a perspectiva da cultura, pois"uma das formas convencionais de uso da cultura é seu direcionamento como um recurso para a melhoria das condições sociais, como na criação de tolerâncias multiculturais e de participação cívica, e no crescimento econômico [...]" (ALMEIDA, 2013, p.42). Mas como instrumentalizar esse papel?

A mediação cultural pode ser a solução. Esta se caracteriza, basicamente, por "processos de diferente natureza cuja meta é promover a aproximação entre indivíduos ou coletividades e obras de cultura e arte" (COELHO, 2012, p.268). Em se tratando de sua aplicação na área biblioteconômica, é preciso considerar, segundo Sandoz (2010, p.4, tradução nossa)², que "a mediação cultural significa para nós os dispositivos que tem a finalidade de despertar, abrir aos usuários o novo, o desconhecido, trabalhando formas, ideias e novos conhecimentos".

Se a literatura estrangeira, principalmente a francesa, chega a abordar a temática da mediação cultural em bibliotecas, a bibliografia brasileira pouco evidencia essa discussão, sendo escassos os debates sobre a função cultural das bibliotecas no país. Isso pode ser observado, por exemplo, em afirmação de Almeida Júnior (1997) quando diz que a literatura da área preocupa-se muito pouco com a função cultural da biblioteca.

A lacuna de pesquisas sobre o tema relacionado à biblioteca pode ser atribuída a uma concentração de estudos sobre mediação cultural em museus, exposições de arte e na área pedagógica, de modo que, segundo Martins e Picosque (2012), são muitas as atuações envolvidas na mediação cultural, porém, sua paisagem conceitual e o fazer da mediação em diferentes situações e lugares é ainda nova e sedenta de pesquisas e reflexões.

A insipiência na literatura nacional sobre mediação cultural em bibliotecas pôde ser constatada examinando-se várias bases de dados, selecionadas a partir da produção de conhecimento nas áreas de Biblioteconomia e Ciência da Informação. Foram realizadas buscas com as seguintes palavras-chave: mediação cultural, mediação cultural em bibliotecas, ação cultural, animação cultural e apropriação cultural. Além disso, também foi possível perceber uma proliferação de textos que abordam a mediação da informação, como constata, por exemplo, o trabalho de Silva (2015, p.94), em que "pode-se, inclusive, afirmar que a mediação da informação vem se constituindo como um dos primados básicos da Ciência da Informação [...]".

Entretanto, quais seriam os benefícios que a mediação cultural traria para as bibliotecas? Alguns dos autores pesquisados apontam caminhos. Segundo o depoimento de Edmir Perrotti, na obra "Mediação cultural para professores andarilhos na cultura, a mediação cultural", "é experiência, é vivencia, é compartilhamento; é participação, ação afirmativa na cultura" (MARTINS; PICOSQUE, 2012, p.135). O movimento de extensão da biblioteca para a comunidade pela via cultural e artística vai ao encontro de novas expectativas colocadas por Quintela (2011, p.64, grifo do autor) em que o "papel da mediação na formação da pratica cultural e na relação que os indivíduos estabelecem com as artes e a cultura adquire um interesse renovado".

\footnotetext{
2 "Dorénavant, la médiation culturelle signifiera pour nous les dispositifs qui ont pour fin d'éveiller, d'ouvrir les usagers à du nouveau, de l'inconnu, des oeuvres, des formes, des idées ou des connaissances nouvelles".
} 
Oliveira e Winer (2016), a seus modos, compreendem a mediação cultural como um campo expandido na atuação dialógica em diversos segmentos e dispositivos voltados para área de cultura, abrangendo instâncias culturais como bibliotecas, museus, teatros, escolas, espaços públicos e outras muitas localidades. Esses espaços garantem uma complexidade à área da mediação cultural no que diz respeito aos aspectos singulares de cada eixo de atuação. Desse modo, torna-se relevante empreender um levantamento de textos tanto na bibliografia brasileira quanto na estrangeira, com ênfase, porém, nos trabalhos produzidos na França, país com produção proeminente sobre o tema, a fim de se explicitar os conceitos emitidos sobre a mediação cultural em bibliotecas.

Ao se levar em consideração a mediação cultural no contexto das bibliotecas é possível perceber os avanços na tentativa de reflexão conceitual e profissional acerca deste campo tanto em âmbito nacional quanto internacional. O objetivo está em refletir acerca do conceito de mediação cultural em bibliotecas e, assim, promover conexões que favoreçam compreender de maneira mais ampla este campo de atuação, tão plural e complexo.

\section{Procedimentos metodológicos}

Como se trata de assunto pouco explorado, optou-se pela pesquisa de abordagem qualitativa e exploratória, tendo como método a pesquisa bibliográfica. Após a revisão de literatura, alguns autores que tratam sobre o tema da mediação foram abordados, como Martín-Barbero (1997) e Martín-Serrano (1978). Em seguida, foram selecionados os trabalhos que versavam especificamente sobre a mediação cultural no espaço social: Caune (1999); Davallon (2007) e Lamizet (1998).

Depois, realizou-se um levantamento bibliográfico na base de dados da École Nationale Supérieure des Sciences de l'Information et des Bibliothèques (ENSSIB), com o intuito de selecionar autores que retratassem a mediação cultural especificamente em bibliotecas: Contenot (2011), Doury-Bonnet (2003), Joli-Coeur (2007) e Sandoz (2010). Além disso, foi realizado um levantamento bibliográfico em âmbito nacional sobre os assuntos mediação cultural na área de Ciência da Informação e mediação cultural em bibliotecas. Para isso, foi utilizada a Base de Dados Referencial de Artigos de Periódicos em Ciência da Informação. Dessa forma, a partir dos múltiplos olhares acerca da temática em questão, buscou-se delinear os conceitos e/ou definições propostos pelos autores nacionais e estrangeiros.

\section{Circunscrevendo a Mediação}

O conceito de mediação procede, principalmente, de duas vertentes filosóficas: a idealista, de origem cristã, e a hegeliana, de tradição marxista (SIGNATES, 1998). A primeira dessas vertentes relaciona-se com a herança teológica, a mediação de Cristo entre Deus e o mundo, a mediação dos santos entre os pecadores e Deus. No âmbito da Filosofia será, pois, pela dialética que a mediação se desenvolverá como importante categoria para se pensar o movimento que constitui o real. Por essa vertente, desenvolvida, sobretudo, a partir de Hegel e posteriormente por Marx, a mediação será relacionada à articulação entre as partes de uma totalidade complexa, sendo a ela atribuída a responsabilidade pela capacidade da passagem entre o imediato e o mediato. Está, portanto, vinculada à ideia de processo e movimento que fundam a dialética.

Tecendo uma perspectiva histórica acerca do termo mediação, Williams (2007) indica que este é dotado de relativa complexidade e que se tornou mais abrangente na medida em que foi sendo utilizado como termo chave por vários sistemas do pensamento moderno. O autor indica que, na língua inglesa, seu mais antigo uso foi feito por Chaucer, na obra The Man of Law's Tale, em 1386, referindo-se ao modo de interceptação entre dois adversários, com vistas à reconciliação. Como categoria filosófica, a mediação atinge seu pleno desenvolvimento em Hegel. Daí o seu caráter dialético, que a impede de ser entendida fora dessa perspectiva de análise, bem como de ser considerada como produto: ela é processo, pois se funda na tensão e no movimento.

Consini (2008) aponta que da noção do termo médio presente em Aristóteles até a "teoria das mediações" de Serrano/Martín-Barbero, um longo e tortuoso percurso foi construído. O livro do espanhol 
Martín-Serrano (1978), "La mediación social", surge dentro da linha de estudos teóricos e metodológicos que se ocupam em analisar, de diferentes perspectivas, o papel da comunicação nas sociedades capitalistas avançadas, abrindo-se para um novo campo das ciências sociais dedicado ao estudo das mediações sociais.

Algumas de suas reflexões mais importantes sobre o tema da mediação compõem o verbete "Mediação" de Silva (1986, p.735). Nesta obra, a abordagem do tema resulta em uma síntese do conceito de mediação como sendo um "sistema de regras e de operações aplicadas para instituir uma ordem a qualquer conjunto de coisas ou de fatos pertencentes a planos heterogêneos da realidade".

Na década seguinte, a questão da mediação adquire expressiva relevância a partir do trabalho de Martín-Barbero (1997) intitulado "Dos meios às mediações: comunicação, cultura e hegemonia". Ao longo de sua obra, o autor desdobra um caleidoscópio de reflexões socioculturais com foco nas manifestações midiáticas (principalmente a televisão). Nesse contexto, o pesquisador hispano-colombiano torna-se responsável pela revivescência da figura das mediações nas pesquisas latino-americanas, estabelecendo uma nova relação entre culturas populares e cultura de massa. Para isso, faz uma análise das mediações acontecidas nos meios de literatura de cordel, no século XVI na Espanha, no rádio, no cinema e na televisão da América Latina contemporânea.

Da análise dos processos sociais à análise comunicacional, o autor inaugurou uma linha teórica em que resga a criatividade dos sujeitos, a complexidade da vida e o caráter interativo exercido com as mídias, observando junto aos processos comunicacionais os dispositivos socioculturais os quais influenciam o modo dos sujeitos envolvidos interpretarem o mundo. Contudo, Martín-Barbero (1997) não defende um conceito fechado de mediação, mas fornece indícios valiosos sobre o local onde as mediações se situam no sistema de produção cultural contemporâneo.

A partir do momento em que o autor uniu os processos sociais à análise comunicacional, inaugurou uma linha teórica a qual resgatou a criatividade dos sujeitos, a complexidade da vida e o caráter interativo exercido com os meios. Assim, a Teoria das Mediações Culturais colocou a academia latino-americana em uma condição de destaque no cenário acadêmico internacional por seu reconhecido esforço multidisciplinar de enxergar o processo de comunicação a partir dos dispositivos socioculturais que influenciam o modo dos sujeitos envolvidos interpretarem o mundo.

\section{Mediação cultural: reflexões conceituais}

Nas últimas décadas, a esfera da cultura sofreu um conjunto de relevantes transformações, ganhando certo reconhecimento político e uma centralidade econômica e social inédita. Essas transformações relacionam-se, em parte, com o modo como o Estado tem procurado reorientar as suas políticas na área cultural, com novas estratégias de intervenção e novas temáticas e agendas, no âmbito das quais se espera que as artes e a cultura venham a dar respostas e contributos significativos para o desenvolvimento socioeconômico das cidades e dos territórios (QUINTELA, 2011).

Por sua vez, também o tema da mediação cultural readquiriu, nas três últimas décadas, bastante relevância nos discursos políticos e programáticos que apelam à formação e atração de públicos para as artes e a cultura. Esse apelo, associado ainda aos princípios da democratização cultural, traduz igualmente as preocupações de sustentabilidade sentidas por agentes e instituições culturais.

María Inés Silva expressa que, nos últimos anos, a mediação cultural tem começado a se posicionar como uma área de especialização no campo da gestão cultural. A autora conta que sua profissionalização constitui uma das prioridades para a institucionalidade cultural no Chile, revertendo-se em uma necessidade para a realização de objetivos políticos de participação, acesso e divulgação, bem como desafio para as instituições culturais no desenvolvimento e formação de públicos.

O presente estudo se embasa em Costa (2009) ao dizer que as primeiras definições do termo mediação cultural provêm de trabalhos instruídos pela linguística. Essa perspectiva, como a de Lamizet (1998), propõe uma definição larga, entendida como um "processo que a sociedade se dá para representar- 
-se própria nos espetáculos e nas práticas artísticas, nos seus monumentos na sua arquitetura e nas suas obras de arte". Nessa perspectiva, o conjunto de atividades produtivas de representação e significação na sociedade participa da mediação cultural.

A mediação representa o imperativo social essencial da dialética entre o singular e o coletivo, e da sua representação em formas simbólicas [...] É o sentido da mediação que constitui as formas culturais de pertença e de sociabilidade dando-Ihes uma linguagem e dando-Ihes as formas e os usos pelos quais os atores da sociabilidade apropriam-se dos objetos constitutivos da cultura que funda simbolicamente as estruturas políticas e institucionais do contrato social (LAMIZET, 1998, p.9, tradução nossa) ${ }^{\mathbf{3}}$.

Para Lamizet (1998), o espaço público é por definição o lugar da mediação cultural, no qual é possível a dialética das formas coletivas e as representações singulares. Os trabalhos do francês Jean Caune sobre a mediação cultural também se baseiam em conceitos forjados na linguística, onde a mediação é que "conduz a palavra do assunto para o outro que ela afeta e põe em movimento" (CAUNE, 1999, p.16, tradução nossa) $)^{4}$ A mediação aparece como uma atividade de produção de sentidos através da língua, no entorno das experiências compartilhadas das obras de arte.

Na perspectiva de Caune (1999), o conceito deve então ser encarado como um fenômeno que permite compreender a divulgação de formas da linguagem ou simbólicas, no espaço e no tempo, que produz significados compartilhados socialmente. Nessa vertente, torna-se relevante pensar a cultura como um fenômeno amplo e abrangente de instituições e práticas se articulando em todas as instituições sociais com as dimensões políticas e econômicas.

Outra definição bastante difundida é a de (DAVALLON, 2007, p.4). Segundo o autor, a mediação cultural: "visa fazer aceder um público a obras (ou saberes) e a sua acção consiste em construir uma interface entre esses dois universos estranhos um ao outro (o do público e o, digamos, do objecto cultural) com o fim precisamente de permitir uma apropriação do segundo pelo primeiro".

Entende-se, assim, que a mediação é instaurada através dos fenômenos da comunicação, tendo caráter histórico e social, e onde se espera que o repertório cultural da coletividade seja transformado através da apropriação cultural. Já no que diz respeito à produção e recepção de objetos culturais, os mediadores tendem a designar o conjunto de ações pelos quais os objetos podem se tornar conhecidos, compreendidos e recebidos. Nessa tônica, Consini (2008) entende o mediador social/cultural como um 'operador de significados' cuja ação define, dentro do sistema, as constantes culturais, com vistas a assegurar a compreensão inequívoca e, consequentemente, possibilitar a previsão e a ação.

Entretanto, Perrotti (2016) acredita que definir a mediação cultural é uma tarefa que se encontra ainda em processo e não se pode afirmar que já se trata, apesar de avanços significativos, de uma noção dotada de estabilidade, referindo-se a realidades e/ou fenômenos tomados em um mesmo e preciso sentido. Entende-se, desse modo, que a mediação cultural pode se tratar de um processo concebido como produção simbólica e material que têm lugar na dinâmica interativa circunscrita em uma relação de sujeito-sujeito-objeto na construção do conhecimento. Observa-se, dessa maneira, a biblioteca apresentada como um dispositivo sociocultural e formada por vários outros dispositivos produtores de sentidos, cujos processos mediadores são todos portadores de significados.

\section{O conceito de mediação cultural em bibliotecas em língua francesa}

Em consulta bibliográfica realizada na base de dados Enssib, foram recuperados (1226) resultados para o termo 'médiation culturelle dans la bibliothèque'. Esse montante demonstra a existência, na literatura

\footnotetext{
3 "La médiation représente limpératif social majeur de la dialectique entre le singulier et le collectif, et de sa représentation dans des formes symboliques. [...] c'est le sens de la médiation qui constitue les formes culturelles d'appartenance et de sociabilité en leur donnant un langage et en leur donnant les formes et les usages par lesquels les acteurs de la sociabilité s'approprient les objets constitutifs de la culture qui fonde symboliquement les structures politiques et institutionnelles du contrat social".

4 "conduit la parole du sujet vers l'autre qu'elle affecte et met en mouvem".
} 
francesa especializada, de uma tradição, desde meados da década de 1990, em discussões sobre o tema em questão.

Em vista disso, foram selecionados alguns dos trabalhos cujos autores discutem o conceito de mediação cultural em bibliotecas. Como Sandoz (2010, p.4, tradução nossa) $)^{\mathbf{5}}$, em seu texto "Repenser la médiation culturelle em bibliothèque publique: participation et quotidienneté" (Repensar a mediação cultural na biblioteca pública: participação e cotidiano), que diz que "a mediação é comumente invocada para responder a perguntas de legitimidade: a legitimidade da biblioteca e do trabalho do bibliotecário". Na noção do autor, essas são perguntas cruciais no momento de se verificar o relativo fracasso na democratização da cultura e nas modalidades de acesso, profundamente transformadas pelo advento das mídias digitais.

Sandoz (2010, p.36, tradução nossa) ${ }^{6}$ diz que a mediação pode ser definida como um conjunto de medidas para se tentar produzir cultura e conhecimento, funcionando de modo acessível aos usuários. E acrescenta: "é toda a ajuda ou apoio que uma pessoa pode oferecer a outra, a fim de tornar o conhecimento mais acessível".

A partir disso, o autor atribui um duplo objetivo na mediação cultural em biblioteca: (a) um objetivo cultural: incentivar a descoberta; (b) um objetivo político: proporcionar um espaço públi-co para o debate democrático, criando laços sociais para a participação na criação de uma identidade comum, para além das diferenças.

Nos argumentos de Sandoz, pode-se observar duas vertentes: a que considera a descoberta, o despertar dos usuários para os novos conhecimentos, portanto, para o maravilhoso desconhecido; e a que enxerga a biblioteca como espaço democrático, onde se constroem interações sociais em busca de uma identidade, incluindo o multiculturalismo. A mediação cultural incide, assim, no papel social e político da biblioteca.

Contenot (2011), em seu artigo "La médiation au servisse de la confluence du musée et de la bibliothèque" (A mediação ao serviço da confluência do museu e da biblioteca), assegura que o principal objetivo da mediação no museu ou na biblioteca é, acima de tudo, a transmissão de conhecimento. A mediação, segundo Contenot (2011, p.12, tradução nossa) ${ }^{\text {: }}$

[...] também ajuda a democratizar o acesso à cultura, a sensibilização por valores culturais e do património, promovendo a descoberta e facilitando o acesso universal às informações. Em ambos os tipos de instituições - museus e bibliotecas - a mediação também permite tranquilizar o público, especialmente quanto ao universo cultural mais remoto, tornando a propriedade cultural mais acessível, desmistificando lugares, dando sentido às coleções através de discursos compreensíveis por qualquer pessoa e finalmente garantindo o apoio ao conhecimento, através do desenvolvimento de procedimentos atraentes e de fácil utilização.

Pode-se observar, nos discursos dos dois autores, opiniões convergentes em relação à mediação cultural: a democratização ao acesso à cultura e o fácil acesso ao conhecimento. Além disso, o Grupo de Investigação em Mediação Cultural (situado no Canadá) publicou, em 2007, o documento: "Définition des termes et des concepts Lexique et bibliographie" (Definição de termos e conceitos - Glossário e Bibliografia). O glossário sobre a mediação cultural, com supervisão de Joli-Coeur (2007), pesquisadora e redatora, teve sua concepção inspirada no dicionário disponível no site do Ministério da Cultura e Comunicação da França.

No documento, a definição geral para a mediação cultural é:

\footnotetext{
5 "La médiation est couramment invoquée pour répondre aux questions de légitimité: légitimité de la bibliothèque, de la prescription qu'elle opère, du travail des bibliothécaires. Ces questions deviennent cruciales à l'heure du constat du relatif échec de la démocratisation culturelle et au moment où les modalités de l'accès à la culture sont profondément transformées par l'avènement du numérique".

6 "Un objectif culturel: favoriser la découverte. Un objectif politique: offrir un espace public de débat démocratique, créer du lien social et participer à la création d'une identité commune au-delà des différences".

7 "Elle contribue également à démocratiser l'accès à la culture, en sensibilisant aux valeurs culturelles et patrimoniales, em encourageant la découverte et en facilitant l'accès universel à l'information. Dans les deux types d'institutions - musées et bibliothèques -, la médiation permet ausside rassurer les publics, en particulier les plus éloignés des univers culturels, en rendant les biens culturels plus accessibles par une demystification des lieux, en donnant du sens aux collections par des discours compréhensibles par tout un chacun et enfin en assurant l'accompagnement vers la connaissance par le développement d'interventions attractives et conviviales".
} 
A mediação cultural é uma forma mais recente de atividades culturais elaboradas - tanto em termos de prática profissional e da relação com o público, como o discurso e ações do Estado - por causa de sua importância política e cívica. Com efeito, a mediação cultural, tal como concebido pelos decisores políticos e as partes interessadas culturalmente, pretende trabalhar em conjunto no sentido de (a vida com o pensamento) e ao nível de vida em coletividade. Este método de intervenção cultural destina-se a restabelecer laços sociais e de inventar novas sociabilidades, buscando fazer a ponte entre o indivíduo e a comunidade, cultura e política, arte e sociedade. Isso implica uma transformação das relações sociais, ao mesmo tempo uma evolução significativa das transmissões culturais (JOLI-COEUR, 2007, p.1, tradução nossa) $)^{\mathbf{8}}$.

Nota-se que Joli-Coeur (2007) apresenta a mediação cultural como área nova, propondo a revitalização dos laços sociais para aproximar os indivíduos da comunidade em busca da cultura, política e arte. A pesquisadora aponta, também, que os objetivos da mediação cultural são tanto o cultural e o educativo quanto o recreativo e o cívico. A mediação cultural, considerando seu alcance geral, está focada nas artes e em todas as práticas culturais da população em conexão com a diversidade, individualidade e estilos de vida.

Já Doury-Bonnet (2003, online, tradução nossa) ${ }^{\mathbf{9}}$, no texto Bibliothèques et médiations (Bibliotecas e mediações), percebe "a mediação cultural como uma forma de organizar o encontro entre a obra e o público, participando na educação cultural". Para a autora, a mediação não é neutra, mas implica em escolhas de valores e estratégias, devendo propiciar espaços para a imaginação e debates em torno da cultura dirigindo-se a todos os públicos.

Ao pesquisar sobre a mediação cultural no Estado de Québec, no Canadá, Wendell (2011, p.1) analisa que há uma concentração "na política de mediação cultural, como um processo de vínculo e bricolagem social, que vem unindo a cultura e o cidadão, através da democratização do acesso pluricultural". O autor conclui, depois de percorrer várias cidades, que a convivência cotidiana do cidadão passa pela cultura e nela atinge uma transformação pessoal pelo resgate de seus valores identitários e da sensibilidade estética; uma mudança social que ocorre pelo aprendizado da relação mais humana e pela compreensão das diferenças.

Nos discursos dos autores está a compreensão de que a mediação cultural pode transformar radicalmente a relação entre o usuário e a instituição. Ela pode permitir que a biblioteca assuma suas funções sociais e políticas. A biblioteca é um lugar onde os laços sociais podem ser tecidos (espalo de encontro e de troca). Na mediação, cuja participação diária pode implementar essa ambição, a cultura, em conseguinte, desempenhará plenamente o seu papel. Finalmente, a mediação como ação participativa permite que o usuário saia da postura de consumidor e participe ativamente na vida da sua comunidade, tornando-se um indivíduo autônomo.

A partir dos autores supracitados, conclui-se que as mediações culturais envolvem laços sociais, agrupando sujeitos de diversas culturas (multiculturalismo) e promovendo o aprendizado e a apropriação cultural por meio das práticas culturais e artísticas. Além disso, a mediação cultural pode colaborar ao introduzir políticas que auxiliem na democratização do acesso à cultura, em ações para sensibilizar a comunidade quanto aos valores culturais e patrimoniais locais, promovendo a descoberta da cultura local e também universal.

\section{Mediação cultural: percepções na Ciência da Informação}

A crítica ao fechamento da Ciência da Informação e da categoria Informação nos anos 1990

\footnotetext{
8 "La médiation culturelle est une forme plus récente et élaborée de l'animation culturelle - tant sur le plan de la pratique professionnelle et de la relation avec le public que du discours et de l'action étatiques - du fait de sa portée politique et civique. En effet, la médiation culturelle, telle que conçue par les décideurs politiques et par les intervenants culturels, ambitionne de travailler conjointement au niveau du sens (la vie avec la pensée) et au niveau du vivre ensemble. Ce mode d'intervention culturelle vise à restaurer le lien social et à inventer de nouvelles socialités en cherchant à faire le pont entre l'individu et la collectivité, la culture et le politique, l'art et la société. Elle implique donc une transformation des rapports sociaux en même temps qu'une évolution importante des transmissions culturelles".

9 "C'est une manière d'organiser la rencontre entre l'œuvre et le public et de participer à léducation culturelle sur le long terme. La médiation n'est pas neutre : elle suppose un choix de valeurs, de stratégies. Elle doit laisser place à l'imaginaire et mettre la culture en débat".
} 
ensejou contemplar o tema da mediação cultural para abrigar os conhecimentos artístico e cultural e não apenas o científico (MOSTAFA, 2012). Gradativamente, a temática vem ganhando interesse nos campos da Informação, da Comunicação e da Cultura em várias partes do mundo. No Brasil, existem cursos de extensão em faculdades privadas, um curso de especialização na Universidade Federal de Pernambuco (UFPE), além de grupos de pesquisa, colóquios e o desenvolvimento de associações de profissionais ligados a áreas culturais. Além disso, também são realizados eventos e publicações, dentre outras ações de relevância nos campos científico e social.

$\mathrm{Na}$ literatura especializada brasileira, primeiro autor a mencionar o termo mediação cultural no contexto da biblioteca foi Flusser (1980), pesquisador e animador cultural francês que esteve, no início dos anos 1980, na Escola de Biblioteconomia da Universidade Federal de Minas Gerais como professor visitante. Flusser (1980) propôs as dimensões fundamentais de uma verdadeira biblioteca pública e expôs as diferenças entre a biblioteca tradicional e a biblioteca-ação cultural, preconizando a procura do contato com o não público e a síntese dialética entre criação e mediação cultural.

Contudo, a mediação cultural discutida através da Ciência da Informação ressurge a partir dos anos 2000, principalmente em autores como Marco Antônio de Almeida e Giulia Crippa (Universidade de São Paulo, Ribeirão Preto) e Edmir Perrotti e Ivete Pierruccini (Universidade de São Paulo, São Paulo). Perrotti e Pieruccini (2007, p.84) entendem a mediação cultural como:

Ação de produção de sentidos e não mera intermediação ou transmissão anódina de signos. Nesse sentido, os dispositivos informacionais são dispositivos de mediação e estão carregados de conceitos e significados. Necessitam, portanto, ser considerados além de suas dimensões funcionais. São processos simbólicos, discursos. Contam. Narram.

Para os autores, o conceito de dispositivo refere-se a um agenciamento de elementos tendo em vista uma finalidade: fazer com que os processos de apropriação simbólica se efetivem. Desse modo, o ato de informar-se é ação e reflexão sobre os aspectos imateriais e materiais da informação, é ação sobre os significados e os significantes, os saberes e seus dispositivos (PERROTTI; PIERUCCINI, 2007).

A mediação cultural, como posicionam Perrotti e Pieruccini (2014), recobre um conjunto multiforme de práticas culturais, considerando uma gama diversificada de manifestações. Nesse sentido, Perrotti e Pieruccini (2007) argumentam que o conceito de mediação cultural se constitui como um conjunto de elementos de diferentes ordens (material, relacional, semiológica) que se interpõem e atuam nos processos de significação.

Nota-se que a mediação se objetiva por meio da comunicação, envolvendo ações, linguagens, suportes, objetos e sujeitos em relações dinâmicas que, para Paschoal (2009, p.22, grifo da autora), "constituem-se e constituem atividades discursivas. Eles dialogam, narram, negociam simbolicamente estratégias e criam performances. Eles articulam e são eles mesmos dispositivos".

Em seu texto"Mediação cultural e da informação: considerações socioculturais e políticas em torno de um conceito", Almeida (2007, p.9) desdobra três aspectos pertinentes acerca dos processos de mediação:

(a) A concepção de mediação como produto/ resultante da ação dos meios de comunicação e informação;

(b) O papel dos mediadores frente às possibilidades abertas (e também fechadas) pelas "novas tecnologias" da sociedade da informação;

(c) A formação de profissionais da Ciência da Informação aptos a enfrentar os desafios que envolvem os dois pontos acima.

Em seu discurso, o autor chama a atenção para o papel que podem desempenhar os meios de comunicação e as novas tecnologias na configuração de um possível espaço público democrático na sociedade. Em 2008, Almeida advoga sobre os desafios cruciais na sociedade da informação: "o de gerar nos indivíduos e grupos as competências simbólicas e comunicacionais para a compreensão dessa nova realidade. Ee é aqui que o mediador joga um papel estratégico e fundamental: o de intermediação cultural entre essa realidade e os sujeitos" (ALMEIDA, 2008, p.21). A função mediadora dos pesquisadores e dos profissionais da informação se faz cada vez mais necessária, buscando conectar os 
indivíduos, bases de conhecimento local, às demais fontes de informação e conhecimento disseminadas na sociedade.

\section{Mediação cultural em bibliotecas no Brasil: um conceito em expansão}

Através dos resultados recuperados na Base de dados Base de Dados em Ciência da informação, até o período de 2015, foi possível estabelecer que pesquisas envolvendo a mediação cultural no contexto das bibliotecas ainda são recentes e escassas, como demonstram os dados no Quadro 1:

Desde a década de 1980, quando surgiram discussões sobre a função cultural das bibliotecas sob a denominação de animação cultural e a ação cultural, pouco se publicou a respeito na literatura especializada brasileira. Os trabalhos listados acima trazem conceitos sobre a mediação cultural pautados em autores franceses, como Davallon (2007) e Lamizet (1998). Apesar dos trabalhos focaram a temática no âmbito das bibliotecas (públicas ou escolares), o conceito de mediação cultural em bibliotecas ainda se encontra em expansão, merecendo investigações acerca de sua complexidade.

De qualquer forma, Souza e Santos (2012) apresentam a importância da mediação realizada nos museus e bibliotecas, assim como a preservação do patrimônio cultural através de seus acervos, além da valorização de práticas que ressaltem o valor da educação para o patrimônio. Os autores fazem uma análise da responsabilidade dos profissionais da informação nessas áreas para a noção de documento, patrimônio, educação e cultura, além de ressaltar a responsabilidade dessas disciplinas para a relevância dos objetos de mediação cultural.
Ao citar as ideias de Lamizet (1998) sobre a mediação cultural, Souza e Santos (2012) avaliam nos mediadores a possibilidade de qualificar ou perceber o acervo de obras e objetos, dos quais irão se tornar visíveis, compreendidos e receptados. Nesse sentido, o mediador participaria dialeticamente da circulação do sistema cultural. O mediador é o terceiro componente que admite dispor questões, favorecendo respostas relevantes aos usuários.

Rasteli e Cavalcante (2014) levam as discussões sobre mediação cultural para o contexto das bibliotecas públicas, propondo verificar as questões que envolvem o conceito junto às práticas de leitura. Para tanto, os autores embasam-se em teóricos como: Coelho (2012); Davallon (2007) e Lamizet (1998). Ao pensarem a biblioteca constituída de dispositivos produtores de sentidos, os autores verificam as ações de mediação cultural como atos de significação, vivenciados com modos de interação entre diferentes experiências culturais.

Em uma abordarem onde a biblioteca escolar é tida como dispositivo cultural de ação, Salcedo e Alves (2014) compreendem que os dispositivos auxiliam no ato de mediar, dando apoio ao mediador, sendo o dispositivo físico ou virtual. Os autores também fazem alusão às competências necessárias ao bibliotecário mediador: o processo de mediação cultural precisa ser feito por profissionais bem capacitados, em lugares bem estruturados e com um resultado que atinja o público alvo, de modo que discussões sejam feitas através de debates e questionamentos.

\section{Conclusão}

Neste contemporâneo, as atividades de mediação cultural vinculam-se aos processos de construção de

Quadro 1. Produção brasileira sobre Mediação Cultural no contexto da Biblioteca.

\begin{tabular}{|c|c|c|c|}
\hline Autor & Título & Ano & Tipo \\
\hline Souza e Santos & $\begin{array}{l}\text { Educação para o patrimônio: mediação cultural na perspectiva dos museus e } \\
\text { bibliotecas: uma experiência interdisciplinar na Ciência da Informação }\end{array}$ & 2012 & Evento \\
\hline Rasteli e Cavalcante & Mediação cultural e apropriação da informação em bibliotecas públicas & 2013 & Artigo \\
\hline Salcedo e Alves & A mediação cultural na biblioteca escolar & 2014 & Artigo \\
\hline Gomes & A biblioteca pública e os domínios da memória, da mediação e da identidade social & 2014 & Artigo \\
\hline
\end{tabular}


sentidos nas bibliotecas. Os espaços das bibliotecas agem como dispositivos produtores de sentidos. Esses dispositivos incluem elementos como as intervenções, as técnicas, os suportes, as práticas, as linguagens, como também questões que envolvem o patrimônio histórico e cultural, a memória local, as identidades culturais, o multiculturalismo, as necessidades culturais e artísticas. Nessa ordem cultural, os acervos, os públicos, as práticas e as missões, cobrem de complexidades as áreas da mediação cultural.

Observamos que seu conceito atrela-se a temas como a democratização cultural, as políticas culturais, a ação cultural e a apropriação cultural.

Através da análise da revisão de literatura, pode-se pensar a mediação instaurada através dos fenômenos da comunicação, de caráter histórico e social, nos quais se espera que o repertório cultural da coletividade (em defasagem) seja transformado através da apropriação cultural.

Na abordagem da cultura, destacando sua condição de instrumento para o desenvolvimento humano, preconiza-se, nas práticas culturais e artísticas, a ideia de poder transformador, quando os elementos culturais são interiorizados e alterados em substância vitalizadora modificando os estados de conhecimento. Isso pode ser chamado de apropriação cultural. Na apropriação cultural o sujeito é visto como ser ativo, participativo, construtor de sentidos em atividades culturais como leitura, escrita e artes. O conceito de mediação ganha destaque por sua centralidade nas interações sociais, cujas práticas podem ser executadas com o auxílio de políticas culturais.

\section{Referências}

ALMEIDA, M. A. Mediação cultural e da informação: considerações socioculturais e políticas em torno de um conceito. In: ENCONTRO NACIONAL DE PESQUISA EM CIÊNCIA DA INFORMAÇÃO, 8., 2007, Salvador. Anais... Salvador: ANCIB, 2007. Disponível em: <http://www.enancib.ppgci.ufba.br/ artigos/GT3--212.pdf>. Acesso em: 26 fev. 2016.

ALMEIDA, M. A. Cultura \& informação: perspectivas para a formação e a atuação do profissional da ciência da informação. In: CASTRO FILHO, C. M. (Org.). Olhares sobre o profissional da ciência da informação. São Paulo: Todas as Musas, 2013.
No momento atual espera-se uma biblioteca dinâmica, o que demanda uma necessidade na formação contínua do bibliotecário, envolvendo-se com as várias questões da comunidade; buscando subsídios através de políticas públicas para o desenvolvimento de ações; refletir e debater acerca da atuação profissional frente a outras práxis que envolvem a cultura e as artes.

Na identificação das práticas de mediação cultural, percebe-se uma ampla gama de possibilidades e intervenções como oficinas de artes, exposições, apresentações artísticas, encontros com artistas, teatro, cinema, audiovisual, fotografia, som, movimento abarcando diferentes formas de linguagens. Na mediação cultural, as bibliotecas são vistas como dispositivos produtores de sentidos, objetivando o contato com várias manifestações culturais. A comunidade constrói significados enquanto vivencia as intervenções de comunicação através das práticas constituídas.

$\mathrm{Na}$ literatura francesa, observamos que o termo mediação cultural revela-se em ações como a revitalização dos laços sociais para aproximar os indivíduos da comunidade em busca da cultura, política e arte. Considerando ainda a descoberta pelo novo, o despertar da comunidade novas informações, portanto, para o maravilhoso desconhecido, almejando das bibliotecas espaços democráticos, de interações sociais e construção de conhecimento.

\section{Colaboradores}

Todos os autores contribuíram na concepção e desenho do estudo, análise de dados e redação final.

ALMEIDA, M. A. Mediações da cultura e da informação: perspectivas sociais, políticas e epistemológicas. Tendências da Pesquisa Brasileira em Ciência da Informação, v. 1, n. 1, 2008. Disponível em: <http://inseer.ibict.br/ancib/index.php/tpbci/ article/view/6/12>. Acesso em: 11 fev. 2016.

ALMEIDA JÚNIOR, O. F. Bibliotecas públicas e bibliotecas alternativas. Londrina: Editora UEL, 1997.

CAUNE, J. Pour une éthique de la médiation: le sens des pratiques culturelles. Saint-Martin-d'Hères (Isère): Presses Universitaires de Grenoble, 1999. 
COELHO, T. Dicionário crítico de política cultural: cultura e imaginário. 2. ed. São Paulo: Iluminuras, 2012.

CONSINI, M. A. Mediação tecnológica na educação: conceito e aplicações. 2008. Tese (Doutorado em Ciências da Comunicação) - Universidade de São Paulo, São Paulo, 2008.

CONTENOT, F. La médiation au service de la confluence du musée et de la bibliothèque. Bulletin des bibliothèques de France [en ligne], v. 56, n. 4, p. 11-15, 2011. Disponible en: <http://bbf.enssib.fr/consulter/bbf-2011-04-0011-002>. Acces en: Sept. 3, 2015

DAVALLON, J. A mediação: a comunicação em processo? Prisma: Revista de Ciências da Informação e da Comunicação. n. 4, 2007. Disponível em:<http://revistas.ua.pt/index.php/ prismacom/article/view/645/pdf>. Acesso em: 25 jan. 2015.

DOURY-BONNET, J. Bibliothèques et médiations. Bulletin des bibliothèques de France, n. 2, 2003. Disponible en: <http://bbf. enssib.fr/consulter/bbf-2003-02-0123-010>. Acces en: Oct. 10, 2015.

FLUSSER, V. Uma biblioteca verdadeiramente pública. Revista da Escola de Biblioteconomia UFMG, v. 9, n. 2, p. 131-138, 1980.

GOMES, H. F. A biblioteca pública e os domínios da memória, da mediação e da identidade social. Perspectivas em Ciência da Informação, v. 19, p. 151-163, 2014. Edição Especial.

JOLI-COEUR, S. Définition des termes et des concepts lexique et bibliographie. In: GROUPE de recherche sur la médiation culturelle. Montréal: Montréal 2007. Disponible en: <http:// montreal.mediationculturelle.org/wpcontent/uploads/ 2010/04/lexique_biblio_2007-2008.pdf>. Acces en: Sept. 12, 2015.

\section{LAMIZET, B. La médiation culturelle. Paris: L'Harmattan, 1998.}

MARTíN-BARBERO, J. Dos meios às mediações: comunicação, cultura e hegemonia. Rio de Janeiro: Editora da URFJ, 1997.

MARTINS, M. C;; PICOSQUE, G. Mediação cultural para professores andarilhos na cultura. 2. ed. São Paulo: Intermeios, 2012.

MARTÍN-SERRANO, M. La mediación social. 2. ed. Madrid: Akal, 1978.

MOSTAFA, S. P. Conhecimento, informação e meios de transmissão cultural. Informação \& Sociedade: Estudos, v. 22, n. 3, p. 95-100, 2012. Disponível em: < http://www.ies.ufpb.br/ojs/ index.php/ies/article/view/14993/8579>. Acesso em: 25 set. 2015.

OLIVEIRA, M. J. S.; WILNER, R. O mediador cultural como profissional reflexivo e o seu campo de formação. In: SALCEDO, D. A. (Org.). Mediação cultural. São Carlos: Pedro \& João Editores, 2016.

PASCHOAL, S. B. N. Mediação cultural dialógica com crianças e adolescentes: oficinas de leitura e singularização. Dissertação (Mestrado em Ciência da Informação) - Universidade de São Paulo, São Paulo, 2009.

PERROTTI, E. Mediação cultural: além dos procedimentos. In: SALCEDO, D. A. (Org.) Mediação cultural. São Carlos: Pedro \& João Editores, 2016.
PERROTTI, E.; PIERUCCINI, I. A mediação cultural como categoria autônoma. Informação \& Informação, v. 19, n. 2, p. 1-22, 2014. Disponível em: <http://www.uel.br/revistas/uel/ index.php/informacao/article/view/19992>. Acesso em: 3 jul. 2015.

PERROTTI, E.; PIERUCCINI, I. Infoeducação: saberes e fazeres da contemporaneidade. In: LARA, M. L. G.; FUJINO, A.; NORONHA, D. P. (Org.). Informação e contemporaneidade: perspectivas. Recife: Néctar, 2007.

QUINTELA, P. Estratégias de mediação cultural: inovação e experimentação no Serviço Educativo da Casa da Música. Revista Crítica de Ciências Sociais, v. 94, p. 63-83, 2011. Disponível em: <http://rccs.revues.org/1531>. Acesso em: 14 fev. 2015

RASTELI, A.; CAVALCANTE, L. E. Mediação cultural e apropriação da informação em bibliotecas públicas. Encontros Bibli: Revista Eletrônica de Biblioteconomia e Ciência da Informação, v. 19, n. 39, p. 43-58, 2014. Disponível em: <https:// periodicos.ufsc.br/index.php/eb/article/view/1518-292 4.2014v19n39p43/26577>. Acesso: em: 30 abr. 2015.

SALCEDO, D. A.; ALVES, R. M. F. A mediação cultural na biblioteca escolar. Biblios, n. 54, p. 82-87, 2014. Disponível em: <http:// biblios.pitt.edu/>. Acesso em: jul. 23, 2015.

SANDOZ, D. Repenser la médiation culturelle em bibliothèque publique: participation et quotidienneté. Mémore d'etude DCB, v. 18, 2010. Disponible: <http://www.enssib.fr/bibliothequenumerique/documents/48311-repenser-la-mediationculturelle-en-bibliotheque-publique-participation-etquotidiennete.pdf>. Accès: 3 ago. 2015.

SIGNATES, L. Estudo sobre o conceito de mediação: grupo de estudos sobre práticas de recepção a produtos midiáticos. Novos olhares, v. 2, n. 2, p. 37-49, 1998.

SILVA, B. (Coord.). Dicionário de ciências sociais. Rio de Janeiro: FGV, 1986.

SILVA, J. L. C. Percepções conceituais sobre mediação da informação. InCID: Revista Ciência Informação e Documentação, v. 6, n.1, p. 93-108, 2015. Disponível em: <http://www. revistas.usp.br/incid/article/view/89731>. Acesso: 12 maio 2015.

SOUZA, A. H. V.; SANTOS, V. R. Educação para o patrimônio: mediação cultural na perspectiva dos museus e bibliotecas: uma experiência interdisciplinar na ciência da informação. In: ENCONTRO NACIONAL DE ESTUDANTES DE BIBLIOTECONOMIA, DOCUMENTAÇÃO, CIÊNCIA DA INFORMAÇÃO E GESTÃO DA INFORMAÇÃO ESCOLA DE CIÊNCIA DA INFORMAÇÃO. 35., 2012, Belo Horizonte. Anais... Belo Horizonte: UFMG, 2012. Disponível em: <http://portaldeperiodicos. eci.ufmg.br/index.php/moci/article/view/2234/1427>. Acesso em: 15 out. 2015.

WENDELL, N. Mediação cultural e a formação de público no Québec. In: CONGRESSO INTERNACIONAL DA ABECAN: 20 anos de interfaces Brasil, 11., 2011, Canadá. Anais... Salvador: UFBa, 2011. Disponível em: <http://www.anaisabecan2011. ufba.br/Arquivos/Wendell-Ney.pdf>. Acesso em: 2 set. 2015.

WILLIAMS, R. Palavras-chave: um vocabulário de cultura e sociedade. Boitempo: São Paulo, 2007. 
